\title{
Distal Transradial Artery Access for Neuroangiography and Neurointerventions
}

\section{Pitfalls and Exploring the Boundaries}

\author{
Isabel Rodriguez Caamaño' $\cdot$ Roger Barranco-Pons ${ }^{1}$ (D) Darren Klass ${ }^{2} \cdot$ Marta de Dios las Cuevas ${ }^{3}$ Oscar \\ Sabino Chirife ${ }^{1} \cdot$ Sonia Aixut ${ }^{1}$
}

Received: 13 January 2021 / Accepted: 6 May 2021 / Published online: 13 July 2021

(c) Springer-Verlag GmbH Germany, part of Springer Nature 2021

\begin{abstract}
Introduction The distal transradial approach (dTRA) is progressively gaining more clinical use in the fields of cardiology and other vascular interventions, as it offers a number of advantages compared to conventional radial approach (TRA). These include lower rates of vascular occlusion which permits preservation of the proximal radial artery for future procedures in the event of a distal occlusion.

Aim To share the experience in the use of dTRA for neurointerventions, showing its advantages, pitfalls as well as sharing our optimized puncture and hemostatic ultrarapid compression protocols to improve the use of this vascular access.

Methods A retrospective analysis of our experience of diagnostic and interventional procedures performed via dTRA using an optimized protocol for puncture and postpuncture compression of the dTRA was performed.

The rate of complications (hematoma and arterial dissection at puncture site) femoral crossover, and assessment of postprocedural stenosis/occlusion with the ultrarapid compression protocol were also assessed.

Results From March 2019 to July 2020 a total of 100 distal radial procedures were carried out and 53 diagnostic angiograms (53\%) and 47 interventional procedures (47\%) were included in the analysis. We achieved a $96 \%$ technical success, with a femoral crossover requirement in 3 cases $(3 \%)$, and one conventional TRA crossover due to puncture failure.

Of the patients 3 presented puncture site hematomas (3\%) with no intervention required, 61 patients $(61 \%)$ underwent the ultrarapid hemostasis protocol in association with a hemostatic pad. Ultrasound follow-up was performed in 20 patients (20\%) at 1-2 months with 1 case of occlusion (5\%) and 2 of radial stenosis (10\%). In all 3 cases proximal radial artery remained patent.

Conclusion The dTRA is a safe and feasible access route for angiography and neurointerventions. Using vasodilators prepuncture, we attained a variable increase in the vascular diameter facilitating puncture and reducing the risk of occlusion and vascular spasm.

A rapid deflation protocol for postpuncture hemostasis does not significantly increase the hematoma rate.
\end{abstract}

Isabel Rodriguez Caamaño

irodriguezca@bellvitgehospital.cat

Roger Barranco-Pons

rbarranco@bellvitgehospital.cat

Darren Klass

darrenklass@gmail.com

Marta de Dios las Cuevas

martalascuevas@gmail.com
Oscar Sabino Chirife

ochirife@bellvitgehospital.cat

Sonia Aixut

saixut@bellvitgehospital.cat

1 Hospital Universitari de Bellvitge, Barcelona, Spain

2 Vancouver, British Columbia, Canada

3 Hospital Universitari Vall d'Hebron, Barcelona, Spain 
Keywords Distal radial access $\cdot$ Patent hemostasis $\cdot$ Neurointerventional radiology $\cdot$ StatSeal $\cdot$ Mechanical thrombectomy $\cdot$ Vascular access

\section{Introduction}

The transradial approach (TRA), and more recently the distal transradial approach (dTRA, at the level of the anatomical snuffbox), have become increasingly more important in the field of interventional neuroradiology as a route for vascular access [1-6]. Traditionally, femoral access (TFA) has been the most frequently used vascular route in the catheterization of supra-aortic trunks.

There is substantial scientific evidence from the field of interventional cardiology [7-9] demonstrating the advantages of TRA in reducing mortality and reducing the risk of local bleeding and other vascular complications [10]. The European Societry of Cardiology (ESC)/European Association for Cardiothoracic Surgery (EACTS) guidelines from 2018 [11] offer A1 evidence of the superiority of TRA over TFA in the endovascular treatment of patients with acute coronary syndrome (independently of risk profile).

TRA is being implemented more and more in the domain of interventional neuroradiology, both for diagnostic angiographic purposes and for interventional procedures. These include hemorrhaging pathology and ischemic stroke [12-14], given the safety of this route of vascular access and the low rate of complications associated with the technique [10].

The early data are so compelling that the technique is being adopted for vascular access in performing diagnostic cerebral angiography, with the anticipation of an increase in the adoption of this vascular access route by neurointerventional radiologists $[5,15]$.

However, there are several pitfalls associated with this technique; the most frequent is radial spasm, which impedes vascular access. Radial artery occlusion (RAO, incidence 0.8-33\%) although almost always asymptomatic, can be significant as it may exclude this access site from future procedures [16-19].

A modification of this access is dTRA, which has several advantages over TRA, one of the most important being a lower rate of vascular occlusion. In a study with 1631 patients, Babunashvili reported vascular occlusion at $1-12$ months to be $0.61 \%$ [20].

In addition, in the event of distal occlusion, because of the emergence of the superficial palmar arch proximal to the point of puncture, the viability of the proximal radial artery may be safeguarded at the level of the forearm $[4$, 21].

The use of dTRA has not become widespread, although recently its utility in carrying out arteriographic diagnosis $[2,4,6]$ and interventional procedures $[2,22]$ has been re- ported. In this study we aim to demonstrate its utility in both diagnostic arteriography and complex procedures, focusing on optimization of the prepuncture vascular caliber and the use of an ultrarapid hemostasis protocol in combination with a potassium ferrate hemostatic patch and a distal compression device.

\section{Material and Methods}

This is a retrospective review of all the diagnostic angiograms and interventional procedures using a dTRA approach carried out in our center from March 2019 to June 2020.

Distal TRA was prioritized over conventional TRA when the distal radial artery predilatation diameter was $>0.17 \mathrm{~mm}$.

\section{Description of the Protocol}

\section{Arterial Puncture}

In our center distal radial access is routinely used in diagnostic angiograms and in some cases of interventional procedures in which the supra-aortic trunk anatomy warrants this route of approach.

It is our institutional standard of care to omit the Allen or Barbeau test. We measure the prepuncture vascular size with ultrasound, given that the size of the artery with respect to the size of the introducer is one of the most important factors in determining the risk of arterial spasm and RAO [23].

The hand is placed in a dorsal flexed position, thereby facilitating advance of devices once the artery is punctured.

Before carrying out arterial puncture we perform an ultrasound measurement (13 MHz hockey stick probe) of the artery size which then serves as a reference; our predilatation cut-off is diameters of less than $1.7 \mathrm{~mm}$ in diagnostic angiograms and $2.2 \mathrm{~mm}$ in interventional procedures.

We select this cut-off diameter arbitrarily but based on the external diameters of the sheaths we use in diagnostic angiograms $(2.2-2.4 \mathrm{~mm})$ and for interventional procedures $(2.7-2.8 \mathrm{~mm})$, to ensure the catheterization and reduce the risk of arterial spasm.

The puncture is made in the anatomical snuffbox above the scaphoid, as this allows easier arterial compression in the event of complications, and postprocedural hemostasis $[2,4,24]$. 
Fig. 1 Ultrasound of the dTRA. a Position of the ultrasound transducer on the anatomical snuffbox in an axial plane, $\mathbf{b}$ ultrasound images of the dTRA in axial acquisition, above the bone plane of the scaphoid, c position of the transducer longitudinally, making it difficult to puncture the snuffbox and assure the bone plane below the puncture site, and $\mathbf{d}$ ultrasound images of the dTRA in longitudinal plane
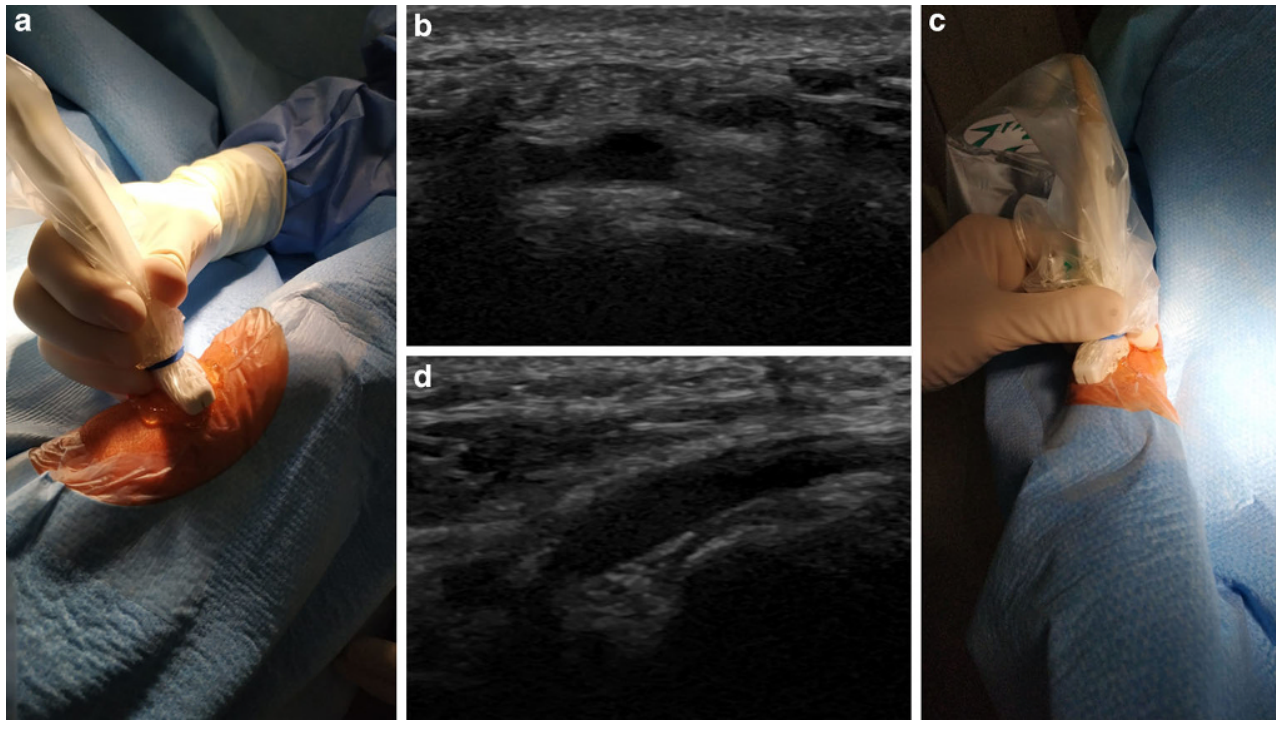

A distal puncture beyond the snuffbox where there is no bony surface but soft tissue offers less chance for compression, and thus an increased risk of hematoma.

It is important to bear this in mind as we will be carrying out access guided by ultrasound, and the position of the transducer may affect the puncture point. The ultrasoundguided puncture can be performed in the longitudinal plane, offering the advantage of a better visualization of the entry of the needle, but it may also lead to puncturing too distal from the snuffbox, as there is no stable surface for the transducer. For this reason, it is advisable to puncture in the axial plane, thereby ensuring that the arterial puncture will be in the anatomical snuffbox and above a bony surface (Fig. 1).

After infiltrating the perivascular soft tissue with an anesthetic cocktail of $1 \%$ lidocaine and $2 \%$ nitroglycerine, we do a systematic second measurement of the postdilatation diameter of the artery, which will be our diameter reference to perform the catheterization. In so doing we attain a variable increase in the vascular diameter that facilitates puncture and reduces the risk of occlusion and vascular spasm.

The artery is punctured with a $21 \mathrm{G}$ needle under ultrasound guidance, with a $0.018^{\prime \prime}$ wire, both included in the radial sheath kit (Slender sheath, Terumo Medical, Somerset, NJ, USA or Ideal, Merit Medical, South Jordan, UT, USA), then inserted is used to introduce the radial sheath.

In the case of diagnostic angiograms we used a 5-6F specific radial sheath.

For $6 \mathrm{~F}$ radial sheath, the external diameter is $2.4 \mathrm{~mm}$, which has the advantage of a smaller external diameter than a conventional $6 \mathrm{~F}$ introducer and similar to a $5 \mathrm{~F}$, due to its thinner wall, but with an internal lumen equivalent of $6 \mathrm{~F}$.

In the case of interventional procedures, we usually opt for a long 6F introducer: Ballast (Balt, Montmorency,
France), Cook Shuttle (Cook Medical, Limerick, Ireland), or Neuron MAX (Penumbra Inc. Alameda, CA, USA), with external diameters of between $2.7 \mathrm{~mm}$ and $2.8 \mathrm{~mm}$, while in some mechanical thrombectomy for ischemic stroke we employ a sheathless flowgate balloon catheter $(2.8 \mathrm{~mm})$.

Once we have inserted the sheath, following aspiration of blood we administer a cocktail of heparin (2000-4000 IU) and verapamil $(5 \mathrm{mg})$, with $200 \mu \mathrm{g}$ of nitroglycerin to reduce the risk of arterial spasm and thrombosis.

We withhold the heparin for those patients who have been administered rtPA and those being treated with longterm oral anticoagulants.

\section{Protocol for Shortened Hemostasis Using StatSeal}

In our center we use a proprietary hemostatic pad (StatSeal, Biolife, Sarasota, FL, USA) with the placement of a pneumatic pressure bracelet (PreludeSYNCTM Radial Compression Device, Merit Medical, South Jordan, UT, USA) as described recently by Hadjivassiliou et al. [25].

Withdrawal of the arterial introducer follows aspiration to verify the absence of a thrombus within the sheath. The introducer is then withdrawn to allow placement of the hemostatic disc and the pneumatic compression bracelet. It is important to remember that placement must be a few millimeters proximal to the puncture point on the skin, because this is the level at which the arterial puncture point is to be found (as a result of the angle of the puncture needle). After fixing of the hemostatic disc with a transparent dressing, the sheath is removed, and the pneumatic bracelet is applied with a volume of $10 \mathrm{ml}$.

After 10 min of compression, the balloon is deflated, and the absence of blood/hematoma is confirmed. If there is no bleeding, the balloon is left in place, completely deflated 

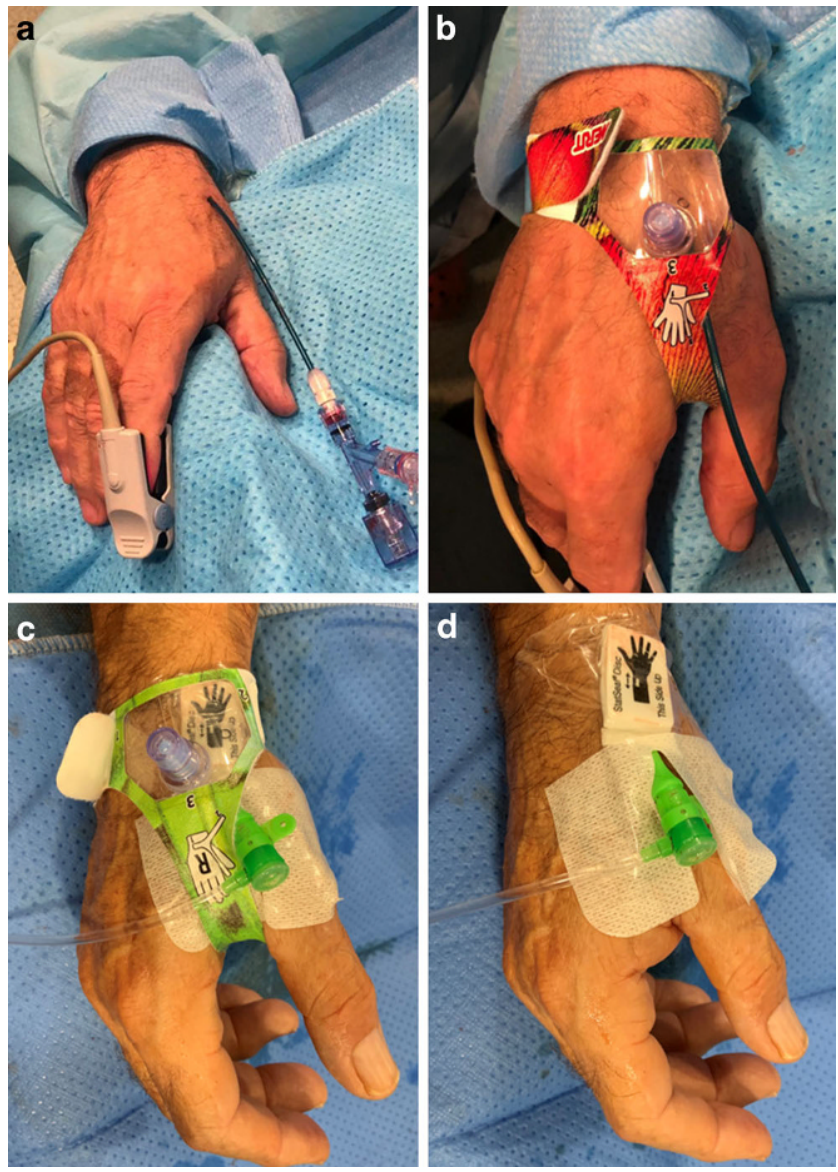

Fig. 2 a,b Conventional postpuncture hemostasis protocol using a pneumatic pressure bracelet, and c,d shortened hemostasis protocol using proprietary hemostatic pad with a pneumatic pressure bracelet, both placed before the withdrawal of the introducer

for $5-30 \mathrm{~min}$. The hemostatic disc is left in place for $24 \mathrm{~h}$ (Fig. 2).

If bleeding or hematoma is seen after 10 min of compression, we inflate the balloon for another $10 \mathrm{~min}$ and check afterwards if there is no hematoma to complete the protocol as describe above.

\section{Protocol for Hemostasis Without StatSeal}

In cases where the hemostatic disc is not used, the protocol dictates inflation of the balloon for $30 \mathrm{~min}$, after which it is deflated, and the absence of bleeding is confirmed. Then there is $30 \mathrm{~min}$ more of compression with the balloon deflated (1h in total) and the bracelet is removed (Fig. 2).

\section{Outcome Measures}

Primary endpoints in the analysis included the procedure type and the effectiveness and safety of the dTRA vascular access related to the need for crossover to TFA and complications associated with this vascular route. Secondary endpoints included the efficacy and safety of the postpuncture ultrarapid hemostasis protocol with postprocedural ultrasound assessment of the radial artery for caliber change and occlusion.

\section{Results}

A total of 100 distal radial procedures were carried out over a period of 16 months (March 2019 to July 2020) in our center, of which 53 were diagnostic angiograms and 47 interventional procedures (Table 1) whereas 98 conventional TRA procedures were performed.

Of the dTRA 86 were right and 12 left, with 2 bilateral dTRA access procedures. A total of 58 men and 42 women were treated, with an average age of 58 years (Range 19-90 years, SD 15.6 years).

All patients underwent ultrasound-guided puncture with a vascular caliber, predilatation, of at least $1.7 \mathrm{~mm}$, following administration of subcutaneous vasodilator.

The average prepuncture vascular caliber in the case of the diagnostic procedures was $2.03 \mathrm{~mm}(1.4-3 \mathrm{~mm}$, SD $0.38 \mathrm{~mm}$ ).

Following administration of the local vasodilator, the average vascular caliber increased to as much as $2.29 \mathrm{~mm}$ $(1.7-3.0 \mathrm{~mm}$, SD $0.48 \mathrm{~mm})$, representing an average increase of $11.3 \%$ ( $p: 0.002$ ).

In those cases with a vascular diameter less than $1.7 \mathrm{~mm}$, after the local vasodilator administration, the diameter was increased to allow us to perform the procedure.

In the case of interventional procedures, the average prepuncture arterial caliber was $2.29 \mathrm{~mm}(1.6-3.4 \mathrm{~mm}$, SD $0.37 \mathrm{~mm}$ ), with an average postdilatation caliber of $2.5 \mathrm{~mm}$ $(1.7-3.9 \mathrm{~mm}, \mathrm{SD} 0.42 \mathrm{~mm})$, representing an average increase of $8.4 \%$ ( $p$ : 0.007).

Overall, crossover to TFA was required in three cases, two in the interventional group, due to difficulty catheterizing the target vessel: one case of external carotid artery (ECA) embolization with tumoral bleeding in the oral cavity, and the other an embolization of an anterior communicating artery (AcomA) aneurysm. The third case was a diagnostic angiogram in which the presence of an arterial loop at the elbow joint rendered the initial procedure impossible to carry out.

In one case of mechanical thrombectomy there was a puncture failure with a focal vascular dissection that limited the use of dTRA and a conventional TRA was used.

In another three cases it was impossible to catheterize the target vessel, but no crossover was carried out. In one case, internal right carotid artery could not be catheterized, in the other two cases it was the left vertebral artery, which in the 
Table 1 dTRA Interventions

\begin{tabular}{|c|c|c|c|c|c|c|c|c|c|}
\hline $\begin{array}{l}\text { Type of inter- } \\
\text { vention }\end{array}$ & $\begin{array}{l}\text { Number of } \\
\text { cases }\end{array}$ & rdTRA & ldTRA & Bilateral & $\begin{array}{l}\text { Mean predi- } \\
\text { latation }(\mathrm{mm})\end{array}$ & $\begin{array}{l}\text { Mean post- } \\
\text { dilatation } \\
(\mathrm{mm})\end{array}$ & Hematomas & Dissection & $\begin{array}{l}\text { StatSeal } \\
\text { protocol }\end{array}$ \\
\hline $\begin{array}{l}\text { Aneurysm em- } \\
\text { bolization }\end{array}$ & 16 & 13 & 2 & 1 & 2.14 & 2.54 & 1 & - & 4 \\
\hline $\begin{array}{l}\text { Mechanical } \\
\text { thrombectomy }\end{array}$ & 14 & 12 & 2 & - & 2.28 & 2.41 & 1 & 1 & 11 \\
\hline Carotid stenting & 3 & 3 & - & - & 2.5 & 2.73 & - & - & - \\
\hline $\begin{array}{l}\text { Intracranial } \\
\text { stenting }\end{array}$ & 5 & 1 & 3 & 3 & 2.07 & 2.27 & - & - & 2 \\
\hline AVF & 3 & 2 & - & 1 & 2.26 & 2.43 & - & - & 2 \\
\hline $\begin{array}{l}\text { ECA emboliza- } \\
\text { tion }\end{array}$ & 2 & 2 & - & - & 2.1 & 2.15 & - & - & 2 \\
\hline AVM & 1 & 1 & - & - & 2.4 & 2.4 & - & - & 1 \\
\hline Occlusion test & 3 & 1 & 2 & - & 1.93 & 2.23 & - & - & 1 \\
\hline
\end{tabular}

$A V F$ arteriovenous fistula, $E C A$ external carotid artery, $A V M$ arteriovenous malformation

end was studied via the subclavian artery using a pressure cuff on the left arm.

The conventional postpuncture hemostasis protocol was utilized in a total of 39 patients and the remaining 61 patients underwent the ultrarapid hemostasis protocol in association with a hemostatic pad (StatSeal).

There were three cases of hematoma. In two of these cases, the postpuncture ultrarapid hemostasis protocol was performed, one of them underwent an angiogram and the other a mechanical thrombectomy following rtPA. In both cases, arterial puncture was not properly made, having the entry site too distal to the snuffbox (Fig. 3).

The third case of hematoma, we performed the conventional postpuncture hemostasis protocol. It was a patient who underwent embolization of a cavernous aneurysm with the placement of an FD type stent, in which we administered 8000 Unit of Heparin during the procedure.

Nevertheless, all three cases of hematoma were not meaningful and were treated conservatively. Arterial patency was preserved in all cases.

All patients were discharged $2 \mathrm{~h}$ after the procedure in both groups regarding other considerations for hospitalization. This is in comparison to patients undergoing conventional radial access where there is a $4 \mathrm{~h}$ hospitalization before discharge.

With the patients undergoing the shortened compression protocol combined with the placement of hemostatic pads, we maintained ultrasound follow-up at 1-12 months to assess postprocedural vascular patency. We scheduled vascular ultrasound to evaluate vascular patency, as well as vascular caliber in relation to postprocedural stenosis.

For circumstances beyond our control (COVID-19) it was not possible to perform ultrasound follow-up on all patients and 20 patients with distal radial access (19 right dTRA and 1 left dTRA) were completely assessed.
We recorded 1 case of total occlusion (1\%), in a patient who had undergone a diagnostic angiogram (vascular caliber $2.6 \mathrm{~mm}$ ), and 2 cases of postprocedural stenosis $(2 \%)$ in patients undergoing interventional procedures ( 1 case of embolization of an aneurysm with an FD stent in a very long procedure, with an initial vascular caliber of $22 \mathrm{~mm}$ and $5 \mathrm{~mm}$ at ultrasound control, and another a diagnostic angiogram with right dTRA, with an initial caliber of $20 \mathrm{~mm}$ and $7 \mathrm{~mm}$ following the procedure).

However, at the proximal level the radial artery remained patent for future procedures, thus the occlusion rate of proximal radial artery was $0 \%$.

\section{Discussion}

The use of TRA access is becoming more common in neurointerventional groups [1, 2, 26, 27], as it is safe, effective, and well-tolerated by patients, and it permits patients to ambulate immediately postprocedure, translating into early discharge and reduced hospitalization costs [27, 28].

In addition, TRA offers a series of advantages such as easier catheterization in the case of type III bovine aortic arches and easier access to the vertebrobasilar system, and it is easier to apply in obese patients and those with severe vascular atheromatous disease in the ileofemoral vessels [27].

Although it has a number of limitations, in terms of possible difficulty in catheterizing the vessel of interest which invokes the need for crossover to TFA [15], this is operatordependent and may be resolved as part of the learning curve $[1,15]$. There are several pitfalls associated with TRA, the most frequent of which is radial spasm, while the most significant is RAO which, with an incidence of $0.8-33 \%$, can compromise vascular viability [19]. 


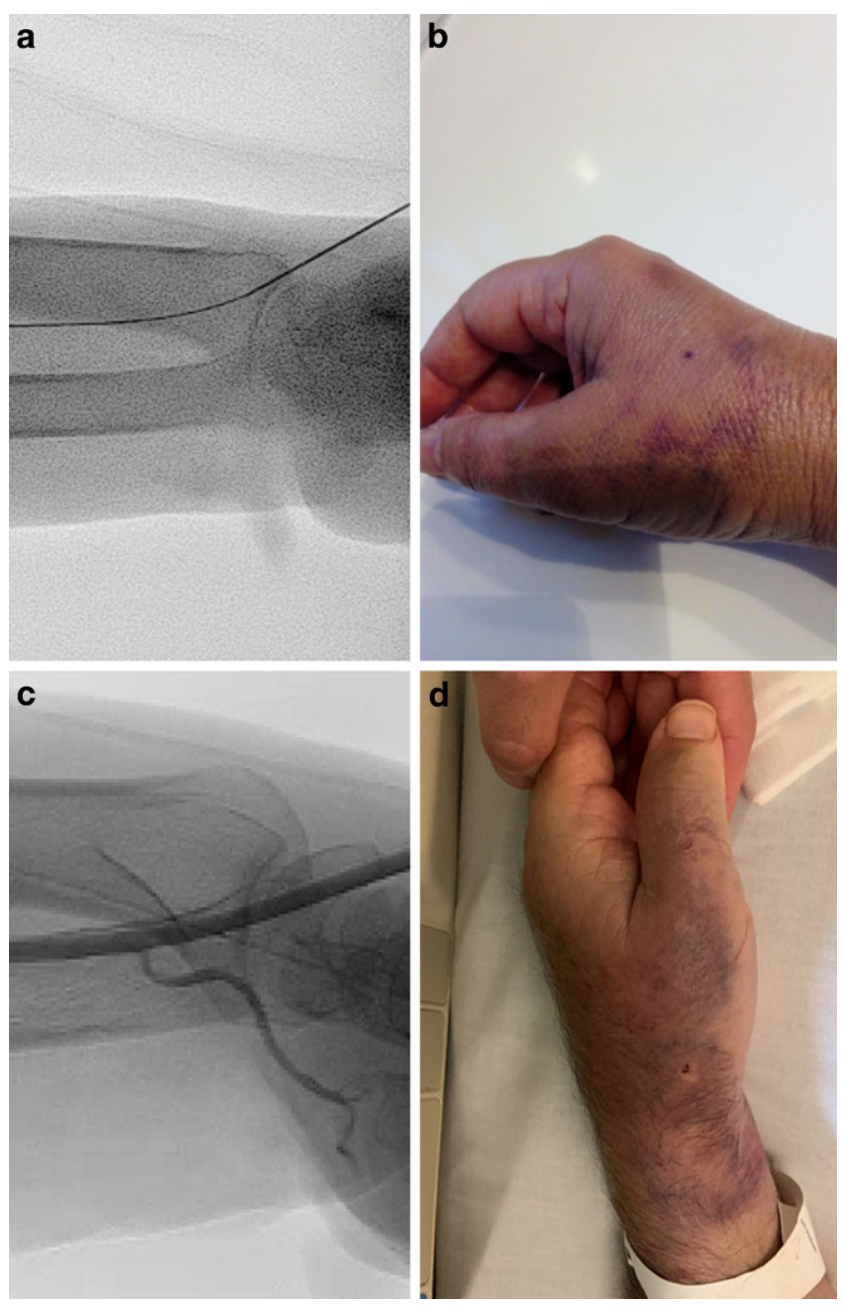

Fig. 3 a,c Angiographic images showing puncture site at the anatomical snuffbox and angiographic run confirm vascular compensation thorough the hand by palmar arch, and $\mathbf{b}, \mathbf{d}$ hematoma complications after dTRA puncture, showing that the puncture was made distal to the bone plane

The most recently implemented dTRA offers a series of advantages in this respect, including a lower risk of RAO $[20,21]$.

Additionally, puncture distal to the superficial palmar arch allows the interventionist to maintain the collateral vascular supply of the hand, as well as to safeguard the integrity of the TRA for future procedures [22].

Furthermore, the size of the distal radial artery in relation to the forearm has been demonstrated not to be clinically significant in terms of caliber change [29].

There are a number of measures that contribute to reducing the risk of RAO, such as the administration of intraarterial vasodilators [30], ultrasound-guided access, measurement of vascular caliber [23], and, above all, attention to the relation between the internal arterial diameter and the external diameter of the introducer sheath used [28]. In our experience the minimum required arterial caliber is $1.7 \mathrm{~mm}$ which can sometimes be achieved using local arterial vasodilators [2].

The use of ultrasound allows the interventionalists to monitor the change in arterial caliber following administration of nitroglycerin, which, owing in part to the change in caliber, can help enable access and/or make it safer and thus decrease occlusion rates by sizing sheaths and equipment appropriately.

We had previous experience in the use of conventional radial access, this allowed us to acquire skills and improve our learning curve in ultrasound vascular puncture and supra-aortic trunks catheterization that we applied for the use of dTRA. We had been progressively changing our preferred route of access to dTRA due its advantages without noticing an increase in time of puncture or catheterization relative to TRA. In the same period of time, we performed more interventions using dTRA $(n=100)$ than TRA $(n=98)$, because we tended to select dTRA whenever was possible.

In our series, with an $8 \%$ caliber change in diagnostic procedures and $11 \%$ in interventions, this difference may be explained by the greater level of sedation administered to the interventional patients, which may have increased the degree of vasodilatation.

This increase in the diameter although it is statistically significant, it is clinically relevant because in many cases it allowed us to perform interventions that otherwise would not have been possible, due to the main limitation of dTRA we encounter, i.e. the diameter of the vessel.

That is why we centered our efforts to optimize our prepuncture protocol because any protocol which helps to increase the vascular caliber and diminish vasospasm is interesting to take in consideration.

In the case of dTRA, ultrasound is in our view mandatory; it helps ensure that the puncture is made above the flat bone, at the point where the radial artery passes over the scaphoid bone, thereby aiding postpuncture hemostasis.

Furthermore, ultrasound control ensures that the access is not made distally to the snuffbox over the interosseus muscles where the risk of local hematoma is increased [2, 22, 24]. For this reason, it is advisable to use ultrasound guidance and perform the ultrasound-guided puncture in the axial plane. The longitudinal plane may enable greater control of the needle for puncture but it can also result in a spacing conflict that impedes puncture above the snuffbox.

In our experience, while the rate of local hematoma is low even in patients on anticoagulants and those who have undergone rtPA, of the 3 cases of hematoma recorded, 2 were attributable to improper puncture technique carried out outside the flat bony area of the snuffbox. Although it seems a high incidence of complications we included minimal local hematoma with no vascular and clinical reper- 
cussion, with no need for other interventions and no need for increasing time of hospitalization.

This is also a factor to consider in terms of postpuncture hemostasis, not only to reduce the risk of hematoma but also, more importantly, to safeguard vascular viability and reduce the risk of stenosis and RAO.

Several protocols for hemostasis in TRA and dTRA have been developed, each in succession seeking to reduce the risk of RAO and prevent postprocedural bleeding.

Current protocols for hemostasis focus on reducing the risk of RAO with shorter compression, permitting radial artery flow while compression is applied. The ULTRA [17] protocol orders ipsilateral ulnar artery transient compression for $1 \mathrm{~h}$, facilitating radial arterial patent hemostasis.

Protocols for rapid hemostasis have also been developed that seek to reduce the compression time to $10 \mathrm{~min}$ by means of a pneumatic bracelet followed by progressive deflation for $15 \mathrm{~min}$, without an increase in the risk of local hematoma [25]. This contrasts with the conventional compression protocols that call for $1 \mathrm{~h}$ of compression. There are also postprocedural hemostasis systems based on the placement of hemostatic patches designed to accelerate vascular healing [31].

With our protocol we have sought not only to reduce compression time with a system of rapid deflation but also to optimize compression in conjunction with the placement of procoagulant hemostatic patches at the point of puncture so as to accelerate healing while also assuring vascular integrity.

In our series there were 1 case of occlusion and 2 cases of postprocedural stenosis, although preserving radial artery patency proximately.

Furthermore, in those patients who did suffer postprocedural occlusion or stenosis, we found an association between the event and prolonged procedure times with much greater caliber of the introducer sheath used in relation to the vascular diameter.

Nonetheless, despite the distal occlusion it was possible to maintain the caliber of the proximal radial artery at the level of the forearm, which represents an added advantage of TRA in the event of the need for future procedures.

While these results are generalizable, our study has some limitations, regarding its retrospective design and due to circumstances beyond our control (COVID-19) it was not possible to perform ultrasound follow-up on all patients, which may have bias in the detection of occlusion rates.

\section{Conclusion}

The use of dTRA is a safe feasible route of access for angiography and neurointerventions, with a low rate of femoral crossover and low rate of complications. A proper puncture at the anatomical snuffbox is mandatory to avoid complications.

The use of subcutaneous nitroglycerin can increase the caliber of the distal radial artery, thereby easing access. A rapid deflation protocol does not significantly increase the hematoma rate.

Funding The author(s) received no financial support for the research, authorship, and/or publication of this article.

\section{Declarations}

Conflict of interest I. Rodriguez Caamaño, R. Barranco Pons, D. Klass, M. de Dios las Cuevas, O.S. Chirife and S. Aixut declare that there are no competing interests.

Ethical standards All procedures performed in studies involving human participants or on human tissue were in accordance with the ethical standards of the institutional and/or national research committee and with the 1975 Helsinki declaration and its later amendments or comparable ethical standards. Informed consent was obtained from all individual participants included in the study. For this type of retrospective study, we had an exemption of approval for our institutional review board.

\section{References}

1. Snelling BM, Sur S, Shah SS, Khandelwal P, Caplan J, Haniff R, Starke RM, Yavagal DR, Peterson EC. Transradial cerebral angiography: techniques and outcomes. J Neurointerv Surg. 2018;10:874-81.

2. Pons RB, Caamaño IR, Chirife OS, Aja L, Aixut S, de Miquel MÁ. Transradial access for diagnostic angiography and interventional neuroradiology procedures: A four-year single-center experience. Interv Neuroradiol. 2020;26:506-13. https://doi.org/10.1177/ 1591019920925711

3. Jo KW, Park SM, Kim SD, Kim SR, Baik MW, Kim YW. Is transradial cerebral angiography feasible and safe? A single center's experience. J Korean Neurosurg Soc. 2010;47:332-7.

4. Brunet MC, Chen SH, Sur S, McCarthy DJ, Snelling B, Yavagal DR, Starke RM, Peterson EC. Distal transradial access in the anatomical snuffbox for diagnostic cerebral angiography. J Neurointerv Surg. 2019;11:710-3.

5. Hoffman H, Jalal MS, Masoud HE, Pons RB, Rodriguez Caamaño I, Khandelwal P, Prakash T, Gould GC. Distal transradial access for diagnostic cerebral angiography and neurointervention: Systematic review and meta-analysis. AJNR Am J Neuroradiol. 2021;42:888-95.

6. Patel P, Majmundar N, Bach I, Dodson V, Al-Mufti F, Tomycz L, Khandelwal P. Distal transradial access in the anatomic snuffbox for diagnostic cerebral angiography. AJNR Am J Neuroradiol. 2019;40:1526-8.

7. Snelling BM, Sur S, Shah SS, Marlow MM, Cohen MG, Peterson EC. Transradial access: lessons learned from cardiology. J Neurointerv Surg. 2018;10:487-92.

8. Piccolo R, Galasso G, Capuano E, De Luca S, Esposito G, Trimarco B, Piscione F. Transradial versus transfemoral approach in patients undergoing percutaneous coronary intervention for acute coronary syndrome. A meta-analysis and trial sequential analysis of randomized controlled trials. PLoS One. 2014;9:e96127. 
9. Valgimigli M, Gagnor A, Calabró P, Frigoli E, Leonardi S, Zaro T, Rubartelli P, Briguori C, Andò G, Repetto A, Limbruno U, Cortese B, Sganzerla P, Lupi A, Galli M, Colangelo S, Ierna S, Ausiello A, Presbitero P, Sardella G, Varbella F, Esposito G, Santarelli A, Tresoldi S, Nazzaro M, Zingarelli A, de Cesare N, Rigattieri S, Tosi P, Palmieri C, Brugaletta S, Rao SV, Heg D, Rothenbühler M, Vranckx P, Jüni P; MATRIX Investigators. Radial versus femoral access in patients with acute coronary syndromes undergoing invasive management: a randomised multicentre trial. Lancet. 2015;385:2465-76.

10. Catapano JS, Fredrickson VL, Fujii T, Cole TS, Koester SW, Baranoski JF, Cavalcanti DD, Wilkinson DA, Majmundar N, Lang MJ, Lawton MT, Ducruet AF, Albuquerque FC. Complications of femoral versus radial access in neuroendovascular procedures with propensity adjustment. J Neurointerv Surg. 2020;12:611-5.

11. Neumann FJ, Sousa-Uva M, Ahlsson A, Alfonso F, Banning AP, Benedetto U, Byrne RA, Collet JP, Falk V, Head SJ, Jüni P, Kastrati A, Koller A, Kristensen SD, Niebauer J, Richter DJ, Seferovic PM, Sibbing D, Stefanini GG, Windecker S, Yadav R, Zembala MO; ESC Scientific Document Group. 2018 ESC/EACTS Guidelines on myocardial revascularization. Eur Heart J. 2019;40:87-165. Erratum in: Eur Heart J. 2019;40:3096.

12. Sur S, Snelling B, Khandelwal P, Caplan JM, Peterson EC, Starke RM, Yavagal DR. Transradial approach for mechanical thrombectomy in anterior circulation large-vessel occlusion. Neurosurg Focus. 2017;42:E13.

13. Haussen DC, Nogueira RG, DeSousa KG, Pafford RN, Janjua N, Ramdas KN, Peterson EC, Elhammady MS, Yavagal DR. Transradial access in acute ischemic stroke intervention. J Neurointerv Surg. 2016;8:247-50.

14. Chen SH, Snelling BM, Sur S, Shah SS, McCarthy DJ, Luther E, Yavagal DR, Peterson EC, Starke RM. Transradial versus transfemoral access for anterior circulation mechanical thrombectomy: comparison of technical and clinical outcomes. J Neurointerv Surg. 2019;11:874-8.

15. Joshi KC, Beer-Furlan A, Crowley RW, Chen M, Munich SA. Transradial approach for neurointerventions: a systematic review of the literature. J Neurointerv Surg. 2020;12:886-92.

16. Jolly SS, Yusuf S, Cairns J, Niemelä K, Xavier D, Widimsky P, Budaj A, Niemelä M, Valentin V, Lewis BS, Avezum A, Steg PG, Rao SV, Gao P, Afzal R, Joyner CD, Chrolavicius S, Mehta SR; RIVAL trial group. Radial versus femoral access for coronary angiography and intervention in patients with acute coronary syndromes (RIVAL): a randomised, parallel group, multicentre trial. Lancet. 2011;377:1409-20. Erratum in: Lancet. 2011;377:1408. Erratum in: Lancet. 2011;378:30.

17. Koutouzis MJ, Maniotis CD, Avdikos G, Tsoumeleas A, Andreou C, Kyriakides ZS. ULnar artery transient compression facilitating radial artery patent hemostasis (ULTRA): A novel technique to reduce radial artery occlusion after transradial coronary catheterization. J Invasive Cardiol. 2016;28:451-4.

18. Caputo RP, Tremmel JA, Rao S, Gilchrist IC, Pyne C, Pancholy S, Frasier D, Gulati R, Skelding K, Bertrand O, Patel T. Transradial arterial access for coronary and peripheral procedures: executive summary by the Transradial Committee of the SCAI. Catheter Cardiovasc Interv. 2011;78:823-39.

19. Stella PR, Kiemeneij F, Laarman GJ, Odekerken D, Slagboom T, van der Wieken R. Incidence and outcome of radial artery occlu- sion following transradial artery coronary angioplasty. Cathet Cardiovasc Diagn. 1997;40:156-8.

20. Babunashvili A. TCT- 810 novel distal transradial approach for coronary and peripheral interventions. J Am Coll Cardiol. 2018;72 (13_Supplement):B323.

21. Corcos T. Distal radial access for coronary angiography and percutaneous coronary intervention: A state-of-the-art review. Catheter Cardiovasc Interv. 2019;93:639-44.

22. Kühn AL, de Macedo Rodrigues K, Singh J, Massari F, Puri AS. Distal radial access in the anatomical snuffbox for neurointerventions: a feasibility, safety, and proof-of-concept study. J Neurointerv Surg. 2020;12:798-801.

23. Saito S, Ikei H, Hosokawa G, Tanaka S. Influence of the ratio between radial artery inner diameter and sheath outer diameter on radial artery flow after transradial coronary intervention. Catheter Cardiovasc Interv. 1999;46:173-8.

24. Hadjivassiliou A, Kiemeneij F, Nathan S, Klass D. Ultrasoundguided access to the distal radial artery at the anatomical snuffbox for catheter-based vascular interventions: a technical guide. EuroIntervention. 2021;16:1342-8. https://doi.org/10.4244/EIJ-D-1900555 .

25. Hadjivassiliou A, Cardarelli-Leite L, Jalal S, Chung J, Liu D, Ho S, Klass D. Safety and efficacy of a truncated deflation algorithm for distal transradial access. J Vasc Interv Radiol. 2020;31:1328-33.

26. Starke RM, Snelling B, Al-Mufti F, Gandhi CD, Lee SK, Dabus G, Fraser JF; Society of NeuroInterventional Surgery. Transarterial and transvenous access for neurointerventional surgery: report of the SNIS Standards and Guidelines Committee. J Neurointerv Surg. 2020;12:733-41.

27. Thakor AS, Alshammari MT, Liu DM, Chung J, Ho SGF, Legiehn GM, Machan L, Fischman AM, Patel RS, Klass D. Transradial access for interventional radiology: Single-centre procedural and clinical outcome analysis. Can Assoc Radiol J. 2017;68:318-27.

28. Mason PJ, Shah B, Tamis-Holland JE, Bittl JA, Cohen MG, Safirstein J, Drachman DE, Valle JA, Rhodes D, Gilchrist IC; American Heart Association Interventional Cardiovascular Care Committee of the Council on Clinical Cardiology; Council on Cardiovascular and Stroke Nursing; Council on Peripheral Vascular Disease; and Council on Genomic and Precision Medicine. An update on radial artery access and best practices for transradial coronary angiography and intervention in acute coronary syndrome: A scientific statement from the American Heart Association. Circ Cardiovasc Interv. 2018;11:e00035.

29. Hadjivassiliou A, Cardarelli-Leite L, Jalal S, Chung J, Liu D, Ho S, Klass D. Left distal transradial access (ldTRA): A comparative assessment of conventional and distal radial artery size. Cardiovasc Intervent Radiol. 2020;43:850-7.

30. Dharma S, Gilchrist IC. Vasodilators and radial artery occlusion: A concept to reduce radial artery occlusion? Circ Cardiovasc Interv. 2018;11:e07011. https://doi.org/10.1161/CIRCINTERVENTIONS. 118.007011

31. Ayyaz Ul Haq M, Nazir SA, Rashid M, Kwok CS, Mubashiruddin S, Alisiddiq Z, Shoaib A, Ratib K, Mamas MA, Nolan J. Accelerated patent hemostasis using a procoagulant disk; a protocol designed to minimize the risk of radial artery occlusion following cardiac catheterization. Cardiovasc Revasc Med. 2019;20:137-42. 